\title{
Functional upper airway obstruction and chronic irritation of the larynx
}

\author{
T.B. Rothe, W. Karrer
}

Functional upper airway obstruction and chronic irritation of the larynx. T.B. Rothe, W. Karrer. @ERS Journals Ltd 1998.

ABSTRACT: Wheezing and dyspnoea are typical symptoms of asthma but can also be found in diseases of the extrathoracic airways. Functional upper airway obstruction may imitate, as well as complicate asthma. Functional upper airway obstruction was first described as a conversion disorder in young females with inspiratory stridor. Subsequently, it was found that functional upper airway obstruction was more often a secondary phenomenon in chronic asthma also involving the expiratory laryngeal airflow.

During a period of $\mathbf{1 5}$ months, we diagnosed six cases of functional upper airway obstruction. Five patients were female and one male, and four were also asthmatics. Three cases showed chronic sinusitis with postnasal drip (PND) and/or gastro-oesophageal reflux. Both disorders may irritate the larynx. Treatment of sinusitis and gastro-oesophageal reflux led to a significant improvement of dyspnoea in all three of these patients.

In asthma refractory to treatment and in the case of an asthmatic exacerbation without obvious cause, functional upper airway obstruction should be excluded to avoid unnecessary treatment with systemic steroids. Some of the possible causative factors of functional upper airway obstruction, such as postnasal drip and gastrooesophageal reflux, are easily treatable.

Eur Respir J 1998; 11: 498-500.
Luzerner Hoehenklinik, Montana, Switzerland.

Correspondence: T.B. Rothe

Leitender Arzt

Luzerner Hoehenklinik

CH-3962 Montana-Vermala

Switzerland

Fax: 41274817364

Keywords: Bronchial asthma gastro-oesophageal reflux

postnasal drip

sinusitis

vocal cord dysfunction

Received: January 91997

Accepted for publication July 101997

Patients

First case reports on functional upper airway obstruction (FUAO) [1, 2] described young female patients with inspiratory laryngeal stridor imitating asthma. This entity is now called vocal cord dysfunction (VCD) [3] and may represent a distinct subform of functional disorders of the larynx. Recently, FUAO has been found more often in asthmatics, where it complicates the primary disease [4]. In this situation, pathological adduction of the vocal cords occurs during inspiration and expiration. Within 15 months, we diagnosed six cases of FUAO amongst our in-patients. Diagnosis of FUAO was based on: 1) a positive history (attacks of breathlessness not responding to $\beta$-agonists and steroids); 2) flattened forced inspiratory flow-volume loop; and 3) nasolaryngoscopy (inspiratory or severe early expiratory adduction of the vocal cords).

Five patients were female and one was male, and four also suffered from asthma. Their ages ranged $42-82 \mathrm{yrs}$. In one case the adduction of the vocal cords was inspiratory, in two cases inspiratory and expiratory, and in three cases there was pure expiratory adduction. One patient was considered to suffer from a conversion disorder. Three patients had significant reflux verified by $\mathrm{pH}$ recordings ( $\mathrm{pH}<4$ more than $5 \%$ of the time), or gastroscopy, respectively. Three patients showed chronic sinusitis on radiography, and two patients suffered from clinically defined postnasal drip (PND).

\section{Patient No. 1}

Patient No. 1, a female aged 62 yrs, had steroiddependent, nonallergic asthma with blood eosinophilia, sinusitis, nasal polyposis and aspirin-intolerance. With spheno-ethmoidectomy and aspirin-desensitization, the daily steroid dose and number of steroid bursts could be reduced. Nevertheless, she often complained of short episodes of dyspnoea, not responding to $\beta$-agonists and being triggered by effort or peak flow measurements. The attacks were accompanied by a conspicuous stridor, being loudest on inspiration.

Nasolaryngoscopy showed a predominantly inspiratory adduction of the vocal cords, that could be reversed with administration of 2\% Xylocaine with epinephrine (fig. 1). Endoscopy revealed a heavy PND due to chronic sinusitis. The nasal discharge contained up to $80 \%$ eosinophils. Twenty four hour $\mathrm{pH}$ measurement in the oesophagus showed significant gastro-oesophageal reflux (GER). After treatment with oral and nasal steroids and a combination of omeprazole and cisapride, the severity and frequency of dyspnoea attacks decreased significantly. 


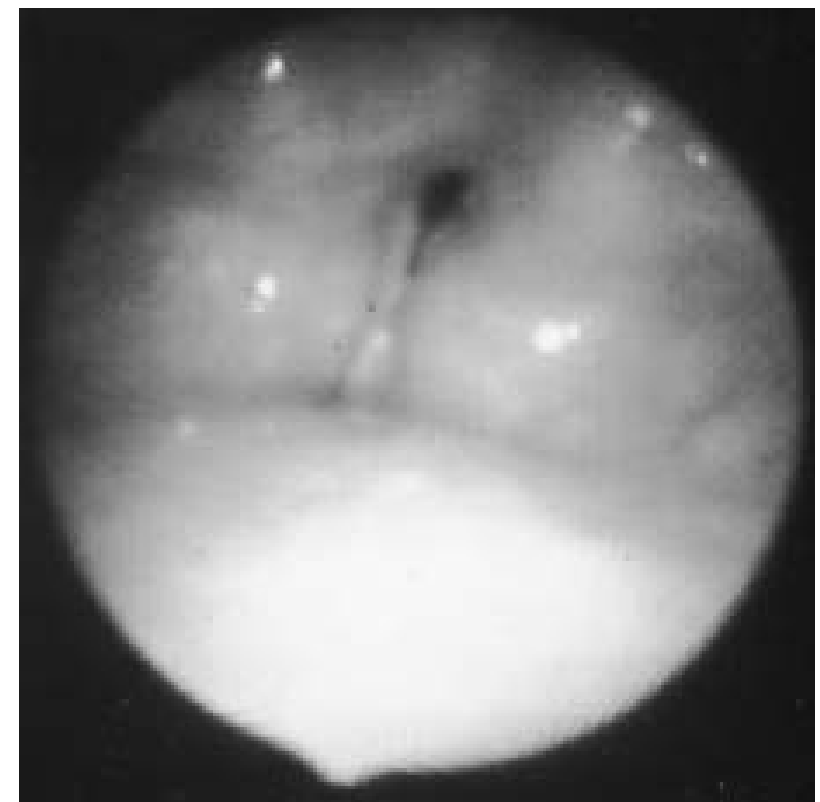

Fig. 1. - Inspiratory adduction of the vocal cords with posterior chink aperture in an asthmatic patient with gastro-oesophageal reflux and postnasal drip on the basis of a chronic sinusitis.

\section{Patient No. 2}

Patient No. 2, a female aged 70 yrs, had a history of chronic bronchitis since 1983. Lung function showed a medium obstruction (not reversible with $\beta$-agonists and an oral steroid burst of 10 days) with check valve phenomenon. With physical effort, a loud expiratory stridor (loudest over the larynx) could be heard. Bronchoscopy revealed a collapse of the central airways. During early expiration, an adduction of the vocal cords occurred. Sinus radiograph and $24 \mathrm{~h} \mathrm{pH}$ measurement were negative.

\section{Patient No. 3}

Patient No. 3, a 42 yr old female, formerly a teacher in Turkey, emigrated to Switzerland with her husband in 1987 and found work as a seamstress in a factory. Since 1993, she had suffered from sudden attacks of severe dyspnoea, which never occurred during sleep. They did not respond to $\beta$-agonists and long-term high-dose oral steroid treatment. Between acute attacks, the flow-volume curve was normal.

Methacholine challenge led to an overall decrease of expiratory flows (Tiffeneau index (forced expiratory volume in one second (FEV1)/forced vital capacity (FVC) in per cent) remained normal) and a flattening of the forced inspiratory flow-volume curve. The patient complained of acute dyspnoea, and a loud inspiratory stridor could be heard over the larynx. The lungs were clear. She refused nasolaryngoscopy. Methacholine challenge was then continued. Up to a cumulative dose of 1,500 $\mu \mathrm{g}$ methacholine, the Tiffeneau index remained stable. At $2,000 \mu \mathrm{g}$, the index decreased, the expiratory flowvolume curve showed a concave shape and wheezing could be heard over both lungs (fig. 2). This was interpreted as a mild asthma complicated by VCD. Reduction of oral steroids to zero did not cause a deterioration of
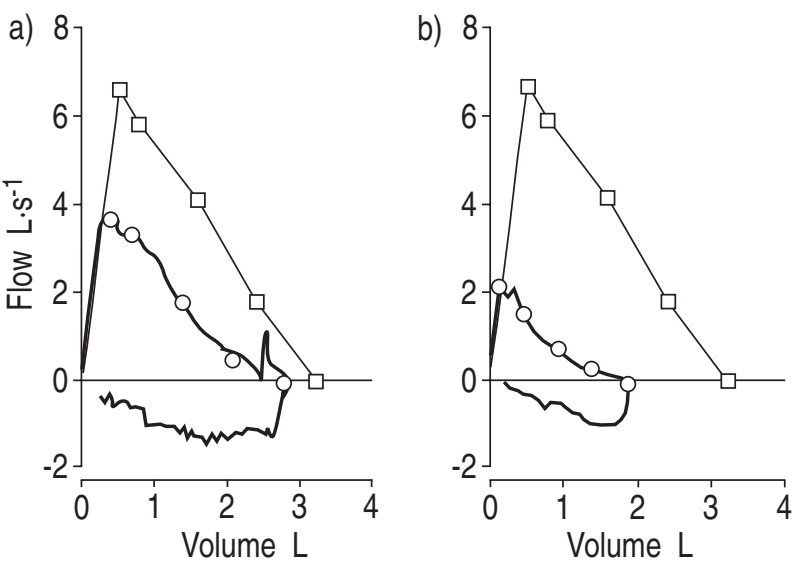

Fig. 2. - Flow-volume curve in the course of methacholine challenge of a patient with vocal cord dysfunction and bronchial asthma. a) $250 \mu \mathrm{g}$ methacholine; b) 2,000 $\mu \mathrm{g}$ methacholine. $\square$ : predicted values; O: measured values.

the asthma. Taking the patient's history into account, it was assumed that a conversion disorder might have been the causal factor for the VCD. PND and GER could not be demonstrated.

\section{Patient No. 4}

Patient No. 4, a female aged 82 yrs, had experienced chronic asthma and sinusitis since 1955, well controlled with topical steroids. During the last 6 weeks, attacks of dyspnoea with loud inspiratory stridor had occurred. Nasolaryngoscopy showed inspiratory adduction of the vocal cords and PND. Radiography revealed an obscured maxillary sinus. Treatment of sinusitis led to a significant decrease of attacks of dyspnoea and stridor.

\section{Patient No. 5}

Patient No. 5, a 78 yr old female, had experienced attacks of breathlessness for some months, with expiratory stridor and aphonia occurring on physical exertion and when speaking loudly. Asthma or bronchitis had never been diagnosed. Lung function and methacholine challenge were normal. Nasolaryngoscopy showed inflammation of the laryngeal mucosa and an expirational adduction of the true and the false vocal cords. A radiograph of the sinus was negative. Twenty four hour $\mathrm{pH}$ measurement revealed massive reflux (for $40 \%$ of the time between 10:00 and 22:00 h). Treatment with omeprazole and cisapride led to a significant improvement of the attacks of breathlessness and aphonia.

\section{Patient No. 6}

Patient No. 6, a male aged 78 yrs, had steroid-dependent nonallergic chronic asthma. An acute deterioration of the asthma caused a fall in FEV1 to $1.28 \mathrm{~L}$, with occurrence of an expiratory stridor over the larynx. Endoscopy revealed a $40 \%$ stenosis of the trachea by intrathoracic goitre, a functional tracheal collapse when coughing of about $70 \%$, and a pathological adduction of the vocal 
cords in early expiration. A sinus radiograph was positive for chronic sinusitis, but no sign of PND was detected. Gastroscopy showed an ulcer and a reflux oesophagitis. After an oral steroid burst and omeprazole therapy, FEV1 increased to $2.16 \mathrm{~L}$ and expiratory stridor subsided.

\section{Discussion}

We have recently diagnosed six cases of FUAO. All patients complained of recurrent attacks of breathlessness not responding to $\beta$-agonists, and previous ambulatory treatment. Four of the six patients also suffered from asthma and one from chronic bronchitis. In one case, with identification of FUAO, we succeeded in stopping oral steroids without deterioration of the asthma.

Three subforms of FUAO could be differentiated in these patients: 1) a patient with features of classical VCD, where inspiratory FUAO seems to be a symptom of an underlying conversion disorder; 2) two patients with central airway instability and severe asthmatic obstruction, respectively. Adduction of the glottic chink aperture during early expiration, also called laryngeal- or auto-positive end-expiratory pressure (PEEP), seems to imitate the effect of pursed lips breathing [5, 6]; and 3) in the remaining three patients, PND and/or GER could be demonstrated.

The vocal cords are primarily designed to prevent penetration of fluids or foreign bodies into the lower airways by rapid closure. Reflux may reach the vocal cords. Development of posterior laryngitis [7] and acute closure of the vocal cords due to massive GER (Mendelson's syndrome) has been described. Therefore, it is not surprising that by irritating the larynx GER may trigger a functional adduction of the vocal cords [8].

In an interesting study, BuccA et al. [9] showed that PND can lead to extrathoracic airway hyperreactivity (EAHR), with significant reduction of the mid-inspiratory flow at $50 \%$ of vital capacity during methacholine challenge. EAHR shares many features with FUAO. PND might, therefore, be another causal cofactor in the development of some forms of FUAO.

Case reports published on FUAO in the past have presented patients with conversion disorders, mostly young females, where inspiratory VCD has imitated asthma [10]. Most of the present patients suffered from steroid-dependent asthma. PND and GER were identified as causal factors of FUAO in 50\% of these patients. Severe asthma complicated by PND and GER might occur more often in later life. This would explain why the mean age in the present group of patients was higher than in classical forms of VCD.

Bearing in mind that some forms of functional upper airway disorder might be caused by chronic irritation of the larynx, as by postnasal drip and gastro-oesophageal reflux, this relationship offers a new approach to the treatment of this condition.

\section{References}

1. Patterson R, Schatz M, Horton M. Münchhausen's stridor: nonorganic laryngeal obstruction. Clin Allergy 1974; 4: 307-310.

2. Christopher KL, Wood RP, Eckert C, Blager FB, Raney RA, Souhrada JF. Vocal cord dysfunction presenting as asthma. $N$ Engl J Med 1983; 308: 1566-1570.

3. Wood RP, Milgrom H. Vocal cord dysfunction. $J$ Allergy Clin Immunol 1996; 98: 481-485.

4. Newman KB, Mason UG, Schmaling KB. Clinical features of vocal cord dysfunction. Am J Respir Crit Care Med 1995; 152: 1382-1386.

5. Wood RP, Jafek BW, Cherniack RM. Laryngeal dysfunction and pulmonary disorder. Otolaryngol Head Neck Surg 1986; 94: 374-378.

6. Collet PW, Brancatisano AP, Engel LA. Upper airway dimensions and movements in bronchial asthma. Am Rev Respir Dis 1986; 133: 1143-1149.

7. Kamel PL, Hanson D, Kahrilas PJ. Omeprazol for the treatment of posterior laryngitis. Am J Med 1994; 96: 321-326.

8. Campbell HA, Perce R. Brief upper airway dysfunction. Respir Med 1994; 88: 125-129.

9. Bucca C, Rolla G, Scappaticci E, Chiampo F, Bugiani M. Extrathoracic and intrathoracic airway responsiveness in sinusitis. J Allergy Clin Immunol 1995; 95: 52-59.

10. Mobeireek A, Alhamad A, Al-Subaei A, Alzeer A. Psychogenic vocal cord dysfunction simulating bronchial asthma. Eur Respir J 1995; 8: 1978-1981. 